\title{
Cultura organizacional: Nível coletivo constitutivo da gestão por competências
}

\section{Organizational culture : Collective constitutive level of competence-based management}

\author{
Célia Cristina Zago ${ }^{1}$ \\ Didier Retour $^{2}$
}

\begin{abstract}
Resumo: A proposta deste estudo é analisar a cultura organizacional como nível coletivo constitutivo do modelo de gestão por competência. Trata-se de uma pesquisa descritiva de abordagem qualitativa que parte de uma reflexão em bases conceituais, complementada por um estudo empírico aplicado em três empresas francesas. Os resultados levam à conclusão de que considerar a cultura organizacional é condição essencial para consolidação teórica do modelo de gestão por competência.
\end{abstract}

Palavras-chave: Cultura organizacional. Competência coletiva. Gestão por competência.

\begin{abstract}
The proposal of this study is to analyze the organizational culture as a collective constitutive level of competence-based management model. This is a descriptive research with quantitative approach based on conceptual reflection complemented by an empirical study of three French enterprises. The results lead to the conclusion that the organizational culture should be considered essential for the consolidation of the competence-based management model.
\end{abstract}

Keywords: Organizational culture. Collective competence. Competence-based management.

\section{Introdução}

O reconhecimento da competência como uma vantagem competitiva tem direcionado um número crescente de organizações à adoção do Modelo Gerencial por Competências em busca de desenvolvimento e sustentabilidade. A formatação atual do modelo tem a França e os Estados Unidos como predecessores prestigiados.

$\mathrm{Na}$ França, várias empresas praticam a lógica da competência desde os anos 80, mas foi a formalização de um acordo assinado na siderurgia francesa, em 1990, que levou à intensificação de adeptos ao modelo, tendo, a partir de 2000, uma significativa adoção por parte também de outras organizações (RETOUR, 2008). Tal interesse se reflete em uma vasta contribuição teórica de pesquisadores franceses sobre esse modelo de gestão, a exemplo de Zarifian, Le Boterf, Retour, Defélix, Dejoux e outros. A perspectiva francesa tem como foco principal a educação e o desenvolvimento dos sujeitos organizacionais que se voltam para a competência organizacional.

Nos Estados Unidos, credita-se a David C. McClelland a introdução do termo competência no contexto organizacional, entretanto as discussões acerca do tema ganharam maior repercussão com o trabalho de Hamel e Prahalad, nos anos 90. A visão norte-americana destaca o desempenho e a tecnologia, e é representada, principalmente, por Boyatzis; Spencer e Spencer; Prahalad e Hamel, entre outros.

A adoção do modelo de Gestão por Competências por empresas brasileiras encontra-se em crescente desenvolvimento. Essa tendência à adesão foi reforçada pela publicação das diretrizes curriculares nacionais para a educação profissional, definidas pelo Conselho Nacional de Educação - CNE em 1999, que assumiram o referencial da competência como ordenador da educação profissional brasileira, ratificando a emergência e consolidação desse modelo de gestão no âmbito acadêmico e profissional (CONSELHO..., 2008).

Assim, as contribuições dos pesquisadores brasileiros aos estudos dessa matéria são consideradas recentes, uma vez que passaram a ser desenvolvidas em maior número a partir dessa primeira década de 2000 - como pode ser constatado ao observarmos o

\footnotetext{
${ }^{1}$ Programa de Pós-graduação em Administração, Departamento de Administração, Universidade Federal da Paraíba - UFPB, Cidade Universitária, CEP 58059-900, João Pessoa, PB, Brasil, e-mail: celiazago@gmail.com

${ }^{2}$ Institut d'Administration des Entreprises - I.A.E, Université Piérre Mendés-France, 525, Av. Centrale, Domaine Universitaire, 38400, Saint-Martin d'Hères, Grenoble, France
} 
conteúdo das publicações nacionais na área - quer seja em livros, em revistas especializadas e/ou em congressos nacionais de Administração e de Engenharia de Produção - reconhecidas como as mais qualificadas de acordo com os critérios de Classificação - QUALIS, da Coordenação de Aperfeiçoamento de Pessoal de Nível Superior - CAPES, do Ministério de Educação do Governo Brasileiro (No Brasil, essas obras constituem, em geral, base para a formação e orientação de administradores em nível de graduação e de pós-graduação latu e stricto sensu, e profissionais da área).

Por ser um modelo ‘jovem', pesquisas apontam que o emprego do conceito de competências continua possuindo um caráter flexível e heterogêneo, e, por vezes, fica restrito apenas à sua concepção (RUAS, 2005; ODERICH, 2005), indicando que a sua ampla aceitação ainda requer maiores esclarecimentos, disseminação e aprofundamento.

Estudos têm sido desenvolvidos com esse interesse, buscando destacar, além dos enfoques individual e organizacional-estratégico - comumente estudados, (McCLELLAND; SPENCER, 1990; LE BOTERF, 2003; ZARIFFIAN, 2003) -, outros níveis de agregação como o coletivo e o ambiental (RETOUR; KROHMER, 2006; ZAGO; SOUZA; BEZERRA, 2007), que sejam capazes de abordar de forma sistêmica toda a sua abrangência conceitual e de melhor distinguir e compreender a natureza das interações entre seus diferentes níveis.

O nível ambiental é discutido por Retour e Krohmer (2006) que analisam a influência dos aspectos extra e interorganizacionais das competências organizacionais, principalmente em organizações que adotam o sistema de clusters, redes e polos de competitividade.

No nível coletivo, as contribuições teóricas concentram-se no destaque das equipes e seus resultados sinérgicos que diferem da simples soma das competências individuais, como defendem Nourdhaug (1996), Pemartin (1999), Amherdt et al. (2000), Bataille (2001), Michaux (2003) (apud RETOUR, KROHMER, 2006) e Zago, Souza e Bezerra (2007).

Entretanto, na perspectiva do coletivo, desponta nas reflexões acadêmicas, outra categoria considerada crucial para o desempenho organizacional: a Cultura Organizacional.

Hatala e Gumm (2006) defendem que uma das principais barreiras ou facilitadores para o sucesso de um programa com base em competência em uma organização é a cultura, pois essa oferece singularidade à organização como um fator de difícil imitação, podendo ser um aspecto imprescindível para a competência organizacional. Porém, num estudo sobre a inter-relação e aplicação do conceito de cultura e competência em uma companhia brasileira internacionalizada, Fischer, Fleury e Urban (2008) concluíram que a articulação entre a cultura e competência organizacionais não foram devidamente esclarecidas e exploradas, sendo essa, uma das intenções deste artigo.

A proximidade à unanimidade entre os estudiosos da administração sobre a relevância da Cultura Organizacional para o alcance das estratégias organizacionais destacou essa ideia como pressuposto básico deste estudo que se propôs refletir se os impactos que a cultura ocasiona na gestão por competência podem categorizá-la como uma dimensão privilegiada para compor a estrutura do modelo.

O estudo perpassa pela reflexão em bases conceituais e pela interlocução entre essas categorias teóricas - cultura e competência organizacionais -, e por uma pesquisa empírica aplicada em três organizações consolidadas (Entende-se por organizações consolidadas as que tenham pelo menos 10 anos de existência), situadas na França (A presente pesquisa que contou com o apoio da CAPES, foi desenvolvida na França, com o engajamento aos estudos do grupo de pesquisa francês - Groupemment de Recherche sur les Attitudes, les Comportementes e les Compétences dans les Organisations/Axe Competénces - GRACCO, vinculado à Universidade l' IAE de Grenoble, cuja proposta é, fundamentalmente, a de instrumentar a gestão das competências coletivas, dando uma realidade tangível à gestão das competências estratégicas, e, por último, de desenhar os contornos de uma gestão das competências ambientais para tanto, as suas pesquisas buscam responder às seguintes questões: Competências individuais, coletivas, estratégicas e ambientais: quais relações, quais efeitos? Quais são os fatores que facilitam ou dificultam as interdependências entre estes quatro componentes da gestão das competências?), com o objetivo de investigar o impacto da cultura para esse tipo de gestão.

Ao analisar essas relações, a reflexão estará voltada para o papel da cultura organizacional como preponderante para as estratégias organizacionais, procurando entendê-la como um nível coletivo constitutivo da competência organizacional.

Depois das reflexões teóricas, o presente artigo expõe a metodologia utilizada e, em seguida, os dados coletados são apresentados e analisados permitindo que considerações sejam traçadas. Ao final, serão indicadas possibilidades de pesquisas posteriores, tendo em vista aspectos centrais e operacionais da percepção da Cultura Organizacional como dimensão para as competências organizacionais.

\section{Fundamentação teórica}

Como já mencionado, credita-se a David C. McClelland a introdução do termo competência no contexto organizacional e, a partir da década de 90, Prahalad e Hamel deram um status estratégico ao tema, levando-o, segundo Parry (1998), ao centro das discussões em muitas organizações. Entretanto, 
desde os anos 80, um grande número de empresas francesas já adotam a competência como lógica de gestão.

Observa-se que a sua forma mais estratégica é associada ao conceito de core competences discutido por Prahalad e Hamell (1990), que são definidas como "[...] as habilidades que permitem à empresa oferecer um benefício fundamental ao cliente [...]" (PRAHALAD; HAMELL, 1995, p. 235); e que as competências individuais e coletivas - numa configuração mais específica - (DUTRA, 2001; FLEURY, 2002; LE BOTERF, 2003; McCLELLAND; SPENCER, 1990; ZARIFFIAN, 2003) se modelam e se estruturam estrategicamente em função das competências organizacionais (RUANO, 2003). Assim, organizações e pessoas, de forma articulada, lado a lado, proporcionam um processo contínuo de troca de competências (DUTRA, 2001), formatando diferentes níveis de agregação da competência - individual, coletivo, e ambiental (RETOUR; KROHMER, 2006).

$\mathrm{O}$ esquema demonstrado na Figura 1 ilustra a formatação teórica atual do modelo de gestão por competências.

\subsection{Competências: recursos articulados}

Em conformidade com a Teoria dos Recursos da Firma - RBV - (PENROSE, 1995; BARNEY,1991), a articulação e interdependência entre os níveis de agregação da competência são essenciais para a criação e mobilização dos recursos que suportam as ações e competitividade organizacional, pois, como dizem Penrose (1995) e Wernerfelt (1984), a competitividade, os limites e as possibilidades de uma firma são determinados pelos limites e possibilidades de seus recursos.

Nessa ótica, pode-se concluir que somente o estoque de recursos não consegue configurar a competência de uma firma, pois é a habilidade ou capacidade dinâmica da mobilização, articulação e arranjo desses recursos que pode levá-la à condição de vantagem competitiva e à condição de difícil imitação (TEECE; PISANO; SHUEN, 1997; PRAHALAD; HAMEL, 1995), pois os processos e interações que suportam as competências organizacionais são constituídos pela articulação e combinação de seus recursos tangíveis e intangíveis e são muito específicos ao contexto, características e cultura de cada empresa (LIPPARINI; CAZZOLA; PISTARELLI, 2000).

Embora pareça lógico o entendimento de que a competência de uma organização depende dos atores sociais nela inseridos, há que se destacar que os sistemas sociais não são compreensíveis senão mediante a compreensão do contexto cultural que atribui significado a símbolos específicos, visto que

[...] onde há vida coletiva surgem efeitos que se sobrepõem ao nível dos indivíduos que compõem a coletividade, refletindo a própria vida coletiva; a sociedade [...] A associação dos homens, sua síntese, produz um todo que se sobrepõe às partes que o formam [...] (DURKHEIM, 1912, p. 73).

Dessa forma, os comportamentos em uma organização não podem ser considerados apenas como uma resultante do somatório das individualidades, mas de uma rede de relações simbólicas interindividuais e intergrupais que os indivíduos estabelecem enquanto sistema social (VALA, 1995 et al., p. 6), que caracterizam a cultura de uma organização.

\subsection{Competências: indivíduos e cultura organizacional}

Uma das questões fundamentais em toda análise institucional é como construir a relação entre instituições e comportamento dos indivíduos. Segundo Hall e Taylor (2003), numerosos institucionalistas enfatizam a natureza altamente interativa dessas relações, na qual cada polo constitui o outro. Se por um lado as instituições são um reflexo dos indivíduos e grupos que as compõem, por outro, quando agem conforme uma convenção social, os indivíduos se constituem simultaneamente como atores sociais e empreendem ações dotadas de significado social, reforçando a convenção a que obedecem. Criam contextos organizacionais ao mesmo tempo que os

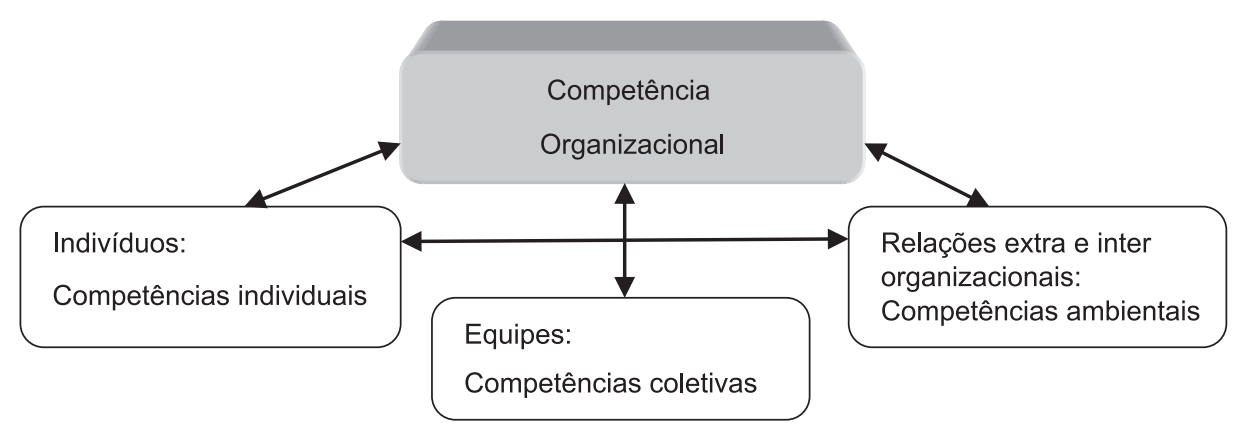

Figura 1. Formatação teórica atual do modelo de Gestão por Competência. 
papéis, projetos pessoais, necessidades, valores, e entendimentos de cada um, do grupo e da própria organização são limitados e reformulados nesses mesmos contextos de interação coletiva. (HALL; TAYLOR, 2003; VALA et al., 1995; MATURANA, 1998).

A percepção da mutualidade de influência entre organização e indivíduos é suportada pelo pensamento neoinstitucionalista, numa perspectiva cultural, que defende que as instituições fornecem modelos morais e cognitivos que permitem a interpretação e a ação (MARCH; OLSEN, 1989).

Numa sociedade, a realidade intersubjetiva é constituída através de partilha de significado entre os seus membros (COONEY, 2007), e essa construção baseia-se no acordo com relação a que conceitos capturar e abstrair da experiência conjunta; em que o sistema de valores associado com o tipo comunal de conhecimento concorrem para o desenvolvimento do senso de identidade, de pertencer a um grupo, e, como este, ser reconhecido. (DAFT; WEICK, 1984 apud LYLES; SCHWENK, 1992).

Durkheim (1912) considera que na vida coletiva surgem efeitos que se sobrepõem ao nível dos indivíduos que compõem a coletividade. $\mathrm{O}$ todo se sobrepõe às partes que o formam dando lugar a um schema cognitivo coletivo (WEICK, 1995).

Nesses termos, sendo a cultura organizacional resultante cognitiva de uma construção social extraída de aspectos importantes da experiência coletiva dos membros de uma sociedade, os quais, uma vez incorporados, passam para o nível do inconsciente coletivo e suportam suas ações, ela é definida por Hofstede (1994, p. 332) como "[...] uma idealização de uma mentalidade coletiva que distingue os membros de um grupo (ou categorias de pessoas) uns dos outros [...]" e por Zago $(2000,2005)$ como modelos mentais coletivos ou visão compartilhada que caracterizam a ação e identidade do grupo.

No âmbito organizacional, esse fenômeno social, denominado de Cultura Organizacional, é construído por numerosas variáveis relacionadas entre si (Uma explicação mais detalhada sobre a composição, formatação e níveis de agregação da cultura organizacional, que inclui aspectos meso e macro influentes, pode ser encontrada em Zago (2000)) e é modelado com a interação das cognições e vivências técnicas, administrativas (estruturas e modelos gerenciais), políticas, estratégicas e táticas, misturadas às cargas psicossociais, que justapõem fatores humanos individuais, relacionamentos grupais, interpessoais formais e informais (TORQUATO, 1991).

A estruturação da cultura depende, portanto, de referenciais comuns do grupo, como conhecimentos, valores, habilidades; experiências e linguagem compartilhadas, e seu engajamento é subjetivo. Esses aspectos, citados como constituintes da cultura organizacional, são definidos por Retour e Krohmer (2006) como sendo atributos da competência coletiva, reforçando o entendimento da inter-relação entre essas duas categorias conceituais.

A influência da organização sobre os comportamentos dos indivíduos, na visão neoinstitucionalista, pode dar-se: a) numa perspectiva normativa - os indivíduos se adaptam às regras e normas da instituição; e/ou b) numa perspectiva cognitiva - que destaca que as instituições influenciam o comportamento ao fornecer esquemas, categorias e modelos morais e cognitivos, que são indispensáveis à ação (HALL; TAYLOR, 2003), levando à semelhança de características da ação dos membros organizacionais (Sobre isso, o sociólogo francês Emile Durkheim (1934) (apud MORGAN, 1996, p. 117) explica que o desenvolvimento da sociedade organizacional cria padrões mais fragmentados e diferenciados de crenças e práticas baseadas na sua estrutura ocupacional, mesclando os padrões tradicionais de ordem social, em termos de ideias comuns, valores e crenças). (BOYER et al., 1995 apud FLEURY; FLEURY, 1997).

Assim, a cultura organizacional e o comportamento nas organizações são fatores intimamente correlacionados e mutuamente determinantes e determinados, à medida que a cultura se consolida como uma resultante dos comportamentos dos atores organizacionais enquanto os conforma. Como conclui Zago (2000, p. 68), "O comportamento é a expressão da cultura que é por ele consolidada".

Tendo que, como modelo mental coletivo a cultura atua como filtro perceptivo que influencia as escolhas e comportamentos da organização, essa pode configurar-se como base de recurso organizacional que suportará ou não a competência demandada.

Assim, cada perfil cultural, como por exemplo, cultura de controle ou de consciência; de punição ou de valorização; individualista ou coletivista; de criatividade ou repetição; de cooperação ou competição; de aprendizagem ou conservação; de autonomia ou centralização; entre outras, poderá ser um fator determinante para a competência organizacional como um recurso único e inimitável.

\subsection{Cultura organizacional - dimensão da competência}

Estudos, como os apresentados a seguir, confirmam as relações entre cultura e competência.

Hatala e Gumm (2006), que desenvolveram pesquisas sobre as influências culturais identificadas na gestão por competências, asseguram que inúmeros estudos como os de Bolman e Deal (1997), Kontoghiorghes et al. (2005), Morgan (1997), Peters (1992), Stone (2002) e Van Wart (1998) demonstraram a existência de uma forte relação entre a cultura interna e o desenvolvimento e desempenho organizacional. 
Outra obra que pode ser citada para a compreensão da cultura interna como uma dimensão constitutiva da competência organizacional é o artigo "Training Failure as a Consequence of Organizational Culture" (BUNCH, 2007), que relata inúmeros estudos que mostram que a cultura organizacional foi um fator impeditivo para a consecução das estratégias organizacionais.

Confirmando essa constatação, o estudo de Ohemeng (2009) expõe como características culturais de algumas organizações públicas influenciaram negativamente o sucesso da implantação de um modelo de governança importado de outra organização pública.

Em um estudo desenvolvido com 102 pequenas e médias empresas na Holanda, com o propósito de explorar a relação entre as características internas, mais especificamente da cultura organizacional e as competências e comportamento da organização, Beugelsdijk, Koen e Noorderhaven (2006) comprovam a hipótese da existência de uma relação entre cultura organizacional e competências. Nesse artigo, os autores provam, por exemplo, que características da cultura, como: confiança, compromisso mútuo, comunicação e estabilidade são determinantes para a competência de relacionamentos interempresas.

A importância da cultura também é reconhecida no artigo de Zula e Chermack (2007, p. 15) que destacam que o conhecimento, que é considerado um dos fatores da competência e tido como o ativo mais valioso para a vantagem competitiva, só ganha repercussão estratégica quando acumulado e embutido na cultura organizacional. "[...] somente assim o conhecimento pode ser considerado como fator crítico para a promoção do desempenho [...]”.

Esses estudos podem ser considerados base para o reconhecimento das relações entre cultura e competência organizacionais, entretanto, para considerarmos a cultura organizacional como um nível coletivo constitutivo da gestão por competências, sentimos a importância de estudar o impacto da cultura organizacional numa perspectiva gerencial da competência.

\section{Metodologia}

Para as reflexões sobre as relações entre a cultura e competência e com o objetivo de investigar o impacto da cultura organizacional para a gestão por competências, o presente estudo desenvolveu uma pesquisa descritiva e exploratória, de abordagem qualitativa, que, além da pesquisa bibliográfica e documental, utilizou uma investigação empírica, para a qual foi considerado adequado o método de estudo de casos múltiplos (GODOY, 1995). A pesquisa foi aplicada em três organizações consolidadas de médio e grande porte, situadas na França, no período de junho a outubro de 2009.
A França foi considerada locus privilegiado para esse estudo por ser um país em que se estima que haja um conhecimento acumulado sobre o modelo, por ser ele aí adotado há quase 30 anos.

Para o enriquecimento da análise, optamos por estudar duas empresas que possuem maior nível de maturidade da aplicação do modelo e uma que se encontra em fase de sua implantação (Para preservação das empresas pesquisadas, bem como dos grupos aos quais pertencem, foram utilizados nomes fictícios para sua identificação neste estudo).

A abordagem básica de coleta de dados foi a entrevista em profundidade com o apoio de um roteiro estruturado e com perguntas abertas que maximizam a descrição e a descoberta.

Em duas empresas, a entrevista foi concedida pelos seus respectivos dirigentes de Recursos Humanos e, em uma delas, por um executivo representante da empresa e da Federação Europeia dos Quadros da Química e das Indústrias. Todos os membros participantes da pesquisa acompanharam ou acompanham o processo de transição das empresas que adotaram o modelo de gestão por competência. Trata-se, portanto, de uma amostra não probabilística e intencional e de seleção racional, que assegura o sujeito-tipo (RICHARDSON et al., 1999), mas que pode ser uma limitação do estudo por expressar a opinião de apenas um membro de cada organização, embora sejam representantes delas.

Sendo um estudo qualitativo, a análise dos dados primou pelos conteúdos e categorização, buscando relacionamentos significativos entre as categorias que corroboraram com os resultados apresentados a seguir.

\section{Apresentação e análise dos casos}

\subsection{Caso METAL}

A METAL, indústria siderúrgica francesa, surgiu quando em 1998 o grupo RONIS comprou a Dicton que havia sido fundada em 1842.

Sediada em Courbevoie - França, com 600 empregados, a METAL SAS tem presença global nos mercados de Automóveis, Mecânica, Petróleo, Gás e Mineração, oferecendo produtos de aço semiacabados, laminados a quente e a frio e de aço endurecido.

Uma crise de viabilidade do setor em 1986 motivou a reação e esforço conjunto dos acionistas e empregados da METAL. Os resultados projetaram-na ao patamar de líder europeia na sua especificidade em 2008 - em contraponto à performance dos grupos nacionalizados da siderurgia que apresentavam perdas entre 1986 e 1997. Este comportamento parece reforçar a percepção de Penrose (1995) e Wernerfelt (1984) de que a competitividade de uma 
firma é determinada pelos limites e possibilidades de seus recursos tangíveis e intangíveis.

Entretanto, se, por um lado, a organização mobilizou seus recursos para criar possibilidades de superação da crise, por outro, o desgaste físico e psicológico gerados, com o tempo, culminou em um clima organizacional de descontentamentos, definindo seus limites.

Afetada pelo clima social interno de descontentamentos - ocasionados pela pressão do esforço empreendido para a recuperação da empresa, em associação à necessidade de adaptação à realidade do grande grupo que a havia adquirido (RONIS USINOR) -, a empresa implantou a Gestão por Competência em 1990, com a missão de desenvolver a versatilidade, mobilidade e melhor clima social, que poderia ser propiciado pela equidade e justiça proposta pelo modelo. Considera-se que a ACAP 2000 (Assinado em 1990, o acordo ACAP 2000 que inaugurou na siderurgia um novo modelo de gestão de Recursos Humanos. Define o emprego como a mobilização das competências, e não mais a ocupação de um posto de trabalho. Ele é portador de uma nova concepção de carreira » BREF - Centre d'Etudes et de Recherches pour les qualifications) tenha sido, também, um reforço importante para a consolidação do modelo na empresa.

Até 1990, fruto de sua tradição, sua estrutura baseava-se em processos e funções e caracterizava-se por uma cultura de individualização, fragmentação e autonomia em consequência do alto nível de independência dados às oficinas, o que, se, por um lado, contribuía para a responsabilização individual e para o surgimento de conflitos ocasionados pela falta de unicidade e de uma linguagem comum, por outro, positivamente contribuía para a inovação e rapidez nos processos.

$\mathrm{Na}$ explicação de seu coordenador de $\mathrm{RH}$, a cultura da METAL é de bricolage, caracterizando-se, portanto, como uma cultura de pequena empresa, em que todos, dentro de cada oficina, se envolvem com tudo e tomam as decisões necessárias para encontrar as soluções.

Analisando as informações coletadas com este estudo, percebe-se que a Gestão por Competências na METAL, foi suportada por características muito únicas, fruto de sua herança cultural de autonomia, podendo ter sido o que propiciou o seu destaque frente às outras empresas do ramo que adotavam uma perspectiva de gestão mais centralizadora.

Para a METAL, o modelo de Gestão por Competências contribuiu para: a) a articulação entre as competências requeridas, mobilizadas, detidas e potenciais (Veja RETOUR, Didier. Le RH de demain face au dossier competènce. Revue management et avenir, 2005/2 no.4), e, portanto, para uma possibilidade de desenvolvimento individual e valorização das pessoas; b) aquisição e utilização de múltiplas competências pela mesma pessoa (devidamente validadas pelo comitê técnico), o que contribuiu para maior mobilidade interna e maior integração entre as oficinas e as pessoas, bem como aumento da empregabilidade dos trabalhadores e maior cobertura das competências requeridas pela empresa; c) ampliação da abrangência da compensação salarial quando considerados os percentuais acrescidos pela acumulação de competências; e d) melhor equidade, o que trouxe maior qualidade ao clima interno da organização.

Agregados aos aspectos da criatividade e autonomia já existentes na cultura, pode-se perceber que o modelo de gestão por competências possibilitou o desenvolvimento de outros aspectos culturais como a flexibilidade e equidade que se tornaram, segundo o seu representante, cruciais para a vantagem competitiva da METAL em relação às demais empresas francesas do setor.

Essa vantagem pode ser mensurada, além da sua liderança, com outros indicadores, como: o reconhecimento do sindicato; a diminuição das greves para $1 / 4$ dos índices praticados; o alcance de $93 \%$ do potencial da "taxa de serviço" (Indicador de qualidade aplicado a todas as usinas do grupo concernente ao respeito ao prazo de entrega do produto ao cliente) contra um índice de $65 \%$ das demais usinas.

A adoção do modelo de gestão por competências na METAL requereu um esforço planejado de alterações de alguns aspectos da sua cultura. A mudança almejada foi estrategicamente incremental e participativa, visando o aumento da confiabilidade no sistema e a confiança e adesão das pessoas à ideia. $\mathrm{O}$ processo de mudanças dos modelos mentais foi sustentado pelas mudanças nos conhecimentos, valores e habilidades das pessoas, através de fóruns de discussões, palestras, cursos e outros meios de comunicação, sendo que, para a montagem do sistema de gestão, houve um cuidado especial de partir da linguagem cotidiana dos trabalhadores.

\subsection{Caso QUIMICAL}

A QUIMICAL - indústria química francesa - atua com produtos em vinil, química industrial e produtos de performance. Presente em 40 países, com um efetivo de aproximadamente 15000 pessoas, possui 80 áreas industriais na Europa, América do Norte e Ásia, 6 centros de pesquisas e filiais de venda em todas as regiões mundo.

Teve como gênese a junção das atividades químicas de dois grandes conglomerados em 1971: a LOTUSELF - indústria de lubrificantes - e a LATOL - indústria petrolífera.

Compôs o conglomerado LATOL até 2004, ano em que algumas atividades químicas consideradas 
não estratégicas para o grupo petrolífero passaram por um processo de spin-off, propiciando a criação da QUIMICAL, que desmembrou-se definitivamente da empresa mãe em 2006.

Pode ser considerada, então, como uma empresa nova, mas antiga. Nova - se vista sob a perspectiva da sua emancipação -, e antiga - se considerado o início da sua estruturação e das suas atividades.

No período de transição, a sua gestão passou 5 anos em inércia, sem qualquer mudança em seus quadros, processos e atividades, entretanto o início da nova gestão em 2006 foi marcado por grandes mudanças, como a reestruturação do seu setor produtivo, a adoção de um modelo próprio de gestão e a busca da criação de uma nova cultura na organização.

A reestruturação produtiva culminou com o encerramento ou venda de atividades consideradas não produtivas ou não estratégicas e, consequentemente, numa redução de seus quadros, na ordem média de 1000 pessoas por ano, com previsão de estabilização em 2012.

No esforço para as mudanças do sistema gerencial, o modelo de gestão por competências foi referendado pela administração da empresa, sendo que, em 2007, como etapa experimental, foi implementado o GPEC (O GPEC foi implantado na empresa em 2007 após um acordo assinado com a maioria dos sindicatos: Confederação Geral dos Executivos; Força Operária; Confederação Francesa dos Trabalhadores, Sindicato Cristão; com exceção do Sindicato Geral dos Trabalhadores - CGT) - Gestion prévisionnelle des emplois et des compétences, que é um sistema sugerido pelo Ministério do Trabalho francês e tem sido amplamente adotado. Assim, a implantação do modelo na empresa pode ser considerada ainda embrionária.

Um diagnóstico sobre a realidade dos recursos humanos na empresa, realizado por uma consultoria externa no início do ano 2008, destacou que carreiras fechadas e o bloqueio da ascensão eram indicadores para uma esclerose interna, indicando que a valorização funcional, ascensão e equidade poderiam não ser características da cultura da empresa.

Os princípios do modelo de gestão por competência que está sendo implantado na empresa configuram-se pela equidade e pela mobilidade no percurso profissional - construída pela diversidade de experiências, pelo desenvolvimento das competências e do aprofundamento do saber fazer, tendo como referência as funções desempenhadas e as múltiplas competências mobilizadas, e que as oportunidades de desenvolvimento e mobilidade devem estar em consonância com as necessidades dos empregados e da organização. Entretanto, segundo o seu representante, a implementação do novo modelo de gestão na empresa tem sido crivada por grandes dificuldades em consequência da resistência demonstrada pela maioria de seus executivos e do ceticismo reinante na empresa. Esses comportamentos se expressam, principalmente, pelas críticas, desconsideração e boicote velado às atividades propostas pelo $\mathrm{RH}$ da empresa.

Com base na afirmação de Durkheim (1912), de que os sistemas sociais não são compreensíveis senão mediante a compreensão do contexto cultural que atribui significado a símbolos específicos, podemos destacar através deste estudo, alguns aspectos culturais que podem concorrer para o quadro descrito, quais sejam:

- O perfil dos executivos: Os executivos da QUIMICAL, por serem provenientes da LATOL, na qual gozavam de status e poder, herdaram características dessa cultura. Uma das práticas na LATOL, assim como em grande parte das empresas francesas, é compor seu quadro de executivos com egressos das "grandes écoles de gestion", que, pelo seu status, deriva uma autoconfiança em seus próprios estilos de gestão, em detrimento de um novo modelo. Essa condição parece indicar que a cultura existente permite grande autonomia dos executivos, mas, ao mesmo tempo, carece de entrosamento e unicidade entre seus estilos de gestão e os objetivos e estratégias da empresa. É importante ressaltar que 43\% dos executivos da QUIMICAL possuem mais de 50 anos de idade;

- Existência de discrepância entre o discurso e a realidade vivenciada: $\mathrm{O}$ discurso de humanização e equidade proveniente do modelo de gestão por competências é tomado com ceticismo quando comparado à realidade da QUIMICAL marcada por grandes pressões por produtividade, demissões, pré-aposentadorias e sobrecarga de trabalho; e

- O pouco tempo de existência do programa na empresa: Conforme Durkheim (1912), para o desenvolvimento de novos modelos mentais, é necessário tempo de experiências conjuntas do grupo sobre uma determinada realidade.

A cultura da QUIMICAL parece, então, trazer características de conservadorismo, descrença e pouca valorização aos seus trabalhadores, e tem oferecido barreiras significativas para a gestão por competências.

Por outro lado, o processo de institucionalização da gestão por competências parece não atender nem ao princípio de normatização - uma vez que os executivos não se veem obrigados a cumpri-las, nem ao princípio da cognição -, considerando que parece não existir uma consciência formada sobre 
a importância da gestão por competências para os objetivos organizacionais e pessoais.

Assim, uma das questões fundamentais para a QUIMICAL parece ser como construir a relação entre as intenções organizacionais e a percepção dos indivíduos que a compõem, uma vez que traços culturais e descrenças podem, na visão de Hatala e Gumm (2006), ser fatores impeditivos ou restritivos para consolidação do modelo de Gestão por Competências e/ou para as mudanças definidas como essenciais para a competência empresarial.

\subsection{Caso Based - Medical Pharmaceutical Systems}

A BASED COMPANY é uma indústria de dispositivos médicos, líder mundial em sua atividade - com detenção de $75 \%$ do mercado, graças à sua core competence de fabricação de seringas de vidro pré-enchidas com a adoção de uma tecnologia que a distingue no mercado. Atua em 50 países e emprega 28000 pessoas.

Com uma estrutura divisional e seis pontos de produção no mundo (o sétimo encontra-se em fase de instalação), as atividades do grupo, que estão em conformidade com as normas da GMP-Good Manufacturing Practices (Referencial de qualidade das empresas farmacêuticas), englobam equipamentos médicos de amplo espectro, para diagnóstico, cuidados e prevenção da saúde.

Foi fundada em 1897 nos Estados Unidos e se instalou na França em 1958, em Le Pont de Claix, que depois de 1970 passou a ser sua sede social europeia e centro de excelência em nível mundial em sua especificidade.

Suas instalações na França, que empregam 1800 pessoas, subdividem-se em 3 segmentos e níveis de representação: BASED-France, com atividades de Administração e vendas - com representação regional; a BASED-Pharmaceutical Systems, que inclui atividades de Pesquisa e Desenvolvimento - com representação global; e a BASED-Usina Pont de Claix, que foi o local escolhido para este estudo, onde trabalham 900 pessoas. A estrutura do RH acompanha essa subdivisão, sendo que na fábrica há um representante do RH para cada célula que possua mais de 5 pessoas.

Até 2002, a mobilidade salarial das pessoas na usina seguia os padrões de um sistema de grille, com um determinado número de níveis para cada cargo, cuja ascensão dava-se por antiguidade, culminado na estagnação após o trabalhador alcançar o teto de sua grade. Esse problema passou a ser compensado com premiações; ação que também não trouxe resultados concretos, sendo que o descontentamento com o sistema culminou com uma greve curta. As reivindicações dos trabalhadores levaram a administração da usina a implantar, por intermédio de uma empresa externa de consultoria, um novo sistema M\&C-Métiers et Competénces, considerado a sua primeira experiência em gestão por competências.

O sistema tinha uma arquitetura de forma piramidal e definia em sua base as competências provenientes da profissão de cada trabalhador, com possibilidade de agregar novas competências em diferentes domínios, propiciando o desenvolvimento de policompetências (O conceito de Policompetência na empresa é o de capacidade de exercer vários trabalhos e vários domínios como comunicação, motivação-liderança, equilíbrio, etc) ou portfólio de competências. Tinha como princípio criar uma base de recursos para a organização suportada no desenvolvimento das pessoas. Assim, para cada portfólio validado, haveria um aumento salarial correspondente.

Entretanto, na idealização do sistema, não se considerou uma das especificidades da cultura dos trabalhadores da empresa que é o egotismo. De acordo com os estudos de Giguere (2008), os trabalhadores da BASED possuem maior ligação com os interesses próprios que ligação afetiva com a empresa.

Em consequência, as pessoas passaram a buscar formações (e.g. comunicação, fluxo, organização, entre outras) independentemente do nível de agregação desses conhecimentos adquiridos à competência organizacional. Prática que gerou um distanciamento da visão industrial e das necessidades de competência na fábrica, além de aumentar significativamente os gastos com o pessoal. E, como afirmam Teece, Pisano e Shuen (1997) e Prahalad e Hamel, (1995), somente o estoque de recursos não consegue configurar a competência de uma firma, pois é a habilidade ou capacidade dinâmica da mobilização, articulação e arranjo desses recursos que pode levá-la à condição de vantagem competitiva.

Além disso, aspectos de descontentamento foram notados pelos sentimentos de injustiça gerados para aqueles que optavam pelos cursos técnicos - que, verdadeiramente traziam benefício para a empresa - pois, esses, apesar de serem mais difíceis e mais longos, não recebiam uma valorização distinta. Outro aspecto questionado era a falta de padronização dos portefeuilles entre as células.

Diante desse quadro, uma sondagem aplicada junto a uma amostra de 403 trabalhadores em 2005, revelou $83 \%$ das pessoas contra e $17 \%$ a favor de continuar com o sistema M\&C.

A elaboração de um novo projeto foi estrategicamente colocada a cargo da coordenação de RH, que, na visão da administração, tinha melhores conhecimentos sobre a cultura organizacional e as necessidades da usina. Uma consultoria externa atuou como apoio e não como definidora do sistema. 
O novo sistema, batizado de NEO, teve suas bases definidas com a participação dos responsáveis pela produção, que definiram pela preservação da orientação piramidal, mas com foco na competência organizacional. Ao mesmo tempo, deixou de ser um modelo piramidal impermeável para tornar-se piramidal expandido, significando a possibilidade de ascensão interna pela proficiência, o que enseja a possibilidade de valorização do esforço individual, contemplando assim, a característica cultural dos trabalhadores.

No sistema NEO, cujo objetivo foi eliminar o máximo possível as disparidades salariais e buscar um sistema lógico e justo, foram definidos níveis para cada atividade de acordo com a complexidade, tomando-se para isso o cuidado de utilização de uma linguagem clara, com termos que fossem verdadeiramente representativos para os trabalhadores para a denominação e classificação de cada competência, deixando muito bem definido quais competências são necessárias para o desenvolvimento de cada função.

Assim, na implantação desse sistema, algumas características culturais como a valorização individual e a linguagem foram observadas; ao mesmo tempo, outras foram trabalhadas para suportar o novo sistema que, em seus princípios básicos, prima pela transparência e clareza, assertividade, valorização e equidade.

Para a institucionalização desses princípios, além das ações serem prudentemente coerentes com eles, um vasto e planejado programa de comunicação foi colocado em prática, para que todos tivessem a oportunidade de conhecer as regras do sistema, adotando-se, conforme a classificação de Hall e Taylor (2003), uma perspectiva tanto normativa como cognitiva.

$\mathrm{Na}$ análise feita pelo respondente da pesquisa: "hoje as pessoas já esperam e contam com a clareza e transparência" e é essa cultura de transparência que pode levar a maior nível de aceitação e confiabilidade nas relações.

É importante salientar que, apesar da pressão do sindicato, 750 dos 760 trabalhadores assinaram suas novas definições individuais de funções, o que, na visão do entrevistado, pode ser um bom indicador de aceitação.

\subsection{Reflexões e conclusões}

$\mathrm{Na}$ tentativa de entendimento do significado do que seja competência organizacional para melhor desenvolvê-la, visto que o momento teórico a aponta como sendo um fator essencial para a sobrevivência e/ou competitividade das organizações, os estudos avançaram ao considerar que a competência organizacional é determinada pela agregação das competências individuais, grupais e ambientais, como afirmam Retour e Krohmer (2006).

Inúmeros são os estudos que reforçam a interdependência entre estes níveis para a formatação da competência organizacional. Entretanto, como os estudiosos defendem que o comportamento e a competência organizacionais dependem da realidade intersubjetiva criada no contexto das interações sociais na organização, definida como cultura organizacional, que, por sua vez, configura e conforma as ações organizacionais, buscamos, neste estudo, através da realidade de organizações francesas, entender se a cultura organizacional deve ser considerada como um nível de análise para a competência organizacional.

Do relato dos casos apresentado podemos extrair algumas considerações no que concerne ao impacto da cultura organizacional na gestão por competência:

Observa-se que, nas organizações que deixaram de considerar as características culturais da empresa como a QUIMICAL e a BASED - na fase do sistema $M \& C$-, a gestão por competências enfrentou, ou enfrenta, sérias barreiras para a sua operacionalização no momento em que as organizações não buscaram desenvolver "competências culturais" que suportassem a implantação do novo modelo de gestão. Essa constatação vem reforçar a necessidade da congruência entre os fatores: cultura e estratégias organizacionais.

Por outro lado, a METAL e a BASED - fase do sistema NEO -, que consideraram aspectos da cultura existente, não enfrentaram os mesmos problemas. Ao investirem nas mudanças das "competências culturais" necessárias, por meio de um processo de institucionalização cognitiva que utilizou como ferramenta a comunicação em diversas perspectivas, ambas consideraram o respeito a aspectos significativos da cultura organizacional, como, por exemplo: a linguagem, a valorização individual e o ritmo das pessoas para a mudança.

Os efeitos do conhecimento e da consideração ou não da cultura organizacional também foram evidenciados na BASED quando a fase NEO - coordenada por um profissional integrante e conhecedor da cultura organizacional - teve melhores resultados que a fase $\mathrm{M} \& \mathrm{C}$ - coordenada por um consultor externo.

No caso da QUIMICAL, podemos entender que, apesar da indicação da existência de competências individuais - se analisarmos a proveniência acadêmica de seus diretores -, os schemas cognitivos sustentados pelo simbolismo do poder, fruto da consolidação cultural existente na empresa, parecem sobrepor e limitar as mudanças propostas para a busca da competência organizacional, uma vez que, como indica a RBV, essa não depende somente das competências individuais, grupais ou de suas interações ambientais, mas da capacidade da organização de conhecer, 
articular e mobilizar essas competências, que, neste caso específico, deixou de considerar uma de suas dimensões: a cultura organizacional. A cultura no caso QUIMICAL pode ser vista como um fator restritivo à mudança e da estruturação da competência organizacional.

Assim, uma das questões fundamentais para a QUIMICAL parece ser como construir a relação entre as intenções organizacionais e a percepção dos indivíduos que a compõem, uma vez que traços culturais e descrenças podem ser, na visão de Hatala e Gumm (2006), fatores impeditivos ou restritivos para consolidação do modelo de Gestão por Competências e/ou para as mudanças definidas como essenciais para a competência empresarial.

As reflexões propiciadas por esse estudo nos mostram que a competência de uma organização é resultado de um processo de escolhas específicas das pessoas que a compõem, cujos comportamentos são influenciados pela cultura organizacional que suporta o sentimento do que é apropriado fazer no âmbito da organização.

Tendo que, como modelo mental coletivo, a cultura atua como filtro perceptivo que influencia as escolhas e comportamentos da organização, essa pode configurar-se como base de recurso organizacional que suportará ou não a competência demandada, sugerindo que, a competência de uma organização depende intrinsecamente da articulação de seus elementos com a cultura organizacional, pois, como afirma Durkheim (1912), os sistemas sociais não são compreensíveis senão mediante a compreensão do contexto cultural.

Essa percepção pode ser reforçada neste estudo uma vez que mostra aspectos significativos do impacto da cultura organizacional sobre as intenções de promoção da competência organizacional. As restrições encontradas na QUIMICAL - através da resistência de seu quadro de diretores e os problemas enfrentados pela BASED - na fase do sistema M\&C - pela sua característica de egotismo, contribuem para o entendimento de que a não observância aos aspectos culturais foi o fator restritivo para a condução das mudanças requeridas para a promoção da competência organizacional, por outro lado, os resultados positivos alcançados da METAL e da BASED - na fase do sistema NEO - concorrem como um indicador de que a cultura organizacional deve ser considerada como um nível constitutivo essencial para a promoção da competência organizacional.

Pelo exposto, concluímos que os níveis de competência: individual, coletivo-grupo/equipes e ambiental - constitutivos da competência organizacional, só podem ser entendidos em toda a sua abrangência se considerados dentro de uma realidade intersubjetiva que é definida e se define pela cultura organizacional, que é, em última instância, os modelos mentais - morais e cognitivos (MARCH; OLSEN, 1989) que norteiam as interpretações e ações organizacionais. Portanto, para o entendimento da abrangência do conceito de competência organizacional não se deve prescindir de considerar a cultura organizacional como um nível coletivo constitutivo para a construção do modelo de gestão da competência organizacional, indicando que a competência organizacional, além das competências individuais, coletivas-grupo/ equipes e ambientais depende da competência cultural organizacional.

Assim, os resultados do estudo levam à conclusão de que a competência cultural organizacional, por permear os demais níveis de agregação da gestão por competência, não só compõe a sua estrutura, como também a suporta, podendo ser, então, considerada como nível coletivo estrutural do seu modelo teórico, como na Figura 2.

Com o exposto, acreditamos que o resultado deste estudo amplia o entendimento sobre os níveis de agregação da gestão por competência, contribuindo com a sua consolidação conceitual e o seu gerenciamento.

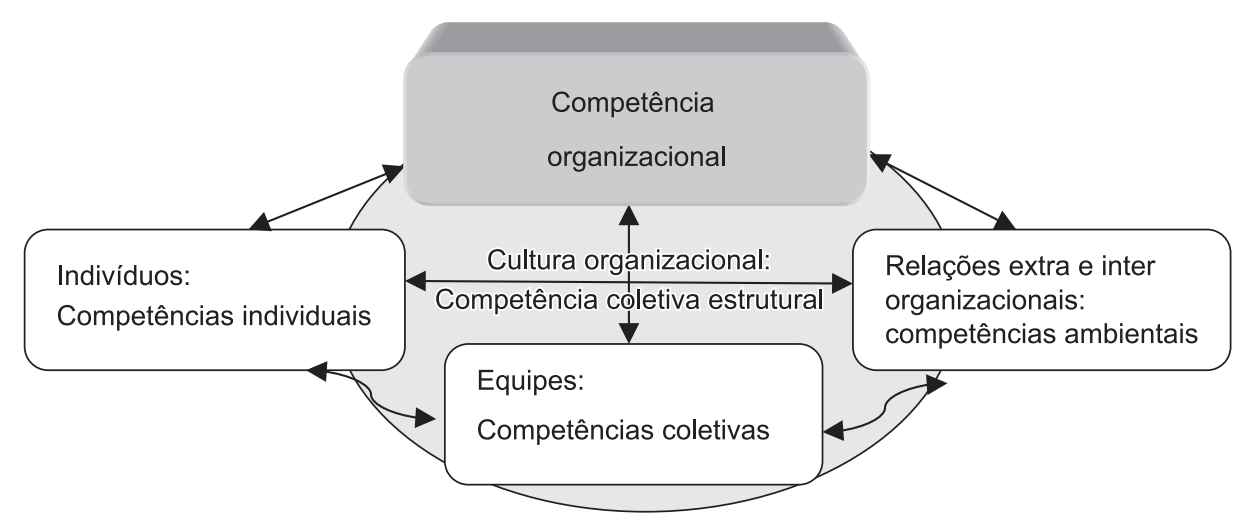

Figura 2. Proposição teórica do estudo para o modelo de Gestão por Competência. 
Com as conclusões extraídas deste estudo, pretendemos estendê-lo para a realidade de organizações em outros países, com o intuito de consolidar ou ratificar seus achados, bem como entender se as diferenças das culturas nacionais repercutem nas competências culturais organizacionais.

\section{Agradecimentos}

À CAPES - Coordenação de Aperfeiçoamento de Pessoal de Nível Superior, que financiou o presente estudo. Ao IAE - Universités Institut d'Administration des Entreprises - locus do estudo. À UFPB - Universidade Federal da Paraíba pelo apoio e incentivo.

\section{Referências}

BARNEY, J. B. Firm resources and sustained competitive advantage. Journal of Management, v. 17, n. 1, p. 99-120, 1991. http://dx.doi. org/10.1177/014920639101700108

BEUGELSDIJK, S.; KOEN, C. I.; NOORDERHAVEN, N. G. Organizational Culture and Relationship Skills. Organization Studies, v. 27, n. 6, 833-854, May 2006. Originally published online.

BUNCH, K. J. Training Failure a Consequence of Organizational Culture. Human Resource Development Review, v. 6, n. 2, p. 142-163, 2007. http://dx.doi. org/10.1177/1534484307299273

CONSELHO NACIONAL DE EDUCAÇÃO - CNE. 2008. Disponível em: <www.mec.gov.br/cne/23>. Acesso em: maio 2008.

COONEY, K. Institutionalization in Action Fields, Organizations, and Agency, Toward a Multilevel Theory. Administration \& Society, v. 39, n. 6, p. 687-718, 2007. http://dx.doi.org/10.1177/0095399707304116

DURKHEIM, E. Les formes élémentaires de la vie religieuse. Paris: Alcan, 1912.

DUTRA, J. S. Gestão de Pessoas com Base em Competências. In: DUTRA, J. S. et al. (Orgs.). Gestão por Competências: um modelo avançado para o gerenciamento de pessoas. Gente: São Paulo, 2001.

FLEURY, M. T. L. Um Resgate Conceitual e histórico dos modelos de gestão de pessoas. In: FLEURY, M. T. L. (Org.). As Pessoas na Organização. Gente: São Paulo, 2002.

FLEURY, A.; FLEURY, M. T. L. Aprendizagem e inovação organizacional: as experiências de Japão, Coréia e Brasil. 2. ed. São Paulo: Atlas, 1997.

FISCHER, A. L.; FLEURY, M. T. L.; URBAN, T. P. Cultura e competência organizacional. In: DUTRA, J. S.; FLEURY, M. T. L.; RUAS, R. L. (Orgs.). Competências: conceitos, métodos e experiências. São Paulo: Atlas, 2008.

GIGUERE, M.-C. Dans un environnement industriel, pourquoi et comment revenir à un système de gestion par les compétences requises après avoir par les compétences détenues?. Mémoire de Master 2 en Management de ressources humaines. IAE de Grenoble, 2008.
GODOY, A. S. Introdução à pesquisa qualitativa e suas possibilidades. São Paulo: Autêntica, 1995.

HALL, P. A.; TAYLOR, R. C. R. The three versions of neo-institutionalism. Lua Nova: Revista de Cultura e Política, n. 58, p. 193-223, 2003. http://dx.doi. org/10.1590/S0102-64452003000100010

HATALA, J.-P.; GUMM, J. C. Managing Organizational Cultural Influences During the Implementation of Competency-Based Training. Advances in Developing Human Resources, v. 8, n. 2, p. 229, 2006. http://dx.doi. org/10.1177/1523422305286154

HOFSTEDE, G. Cultura e organização. Silabo, 1994.

LE BOTERF, G. Desenvolvendo a competência dos profissionais. 3. ed. Tradução de Patrícia Chittoni Ramos Porto Alegre: Reuillard, Artmed, 2003.

LIPPARINI, A.; CAZZOLA, F.; PISTARELLI, P. Como sustentar o crescimento com base nos recursos e nas competências distintivas: a experiência Illycaffé. RAE - Revista de Administração de Empresas, v. 40, n. 2, p. 16-25, abr./jun. 2000.

LYLES, M. A.; SCHWENK, C. R. Top management, strategy and organizational knowledge structures. Journal of Management Studies, v. 29, n. 2, p. 155-174, mar. 1992. http://dx.doi.org/10.1111/j.1467-6486.1992.tb00658.x

MARCH, J. G.; OLSEN, J. P. Rediscovering institutions: The organizational basis of politics. Free Press: New York, 1989.

MATURANA, H. Da Biologia à psicologia. 3. ed. Porto Alegre: Artes Médicas, 1998.

McCLELLAND, D. C.; SPENCER, L. M. Competency assessment methods: history and state of the art. Boston: Hay McBer Research Press, 1990.

MORGAN, G. Imagens da Organização. São Paulo: Atlas, 1996.

ODERICH, C. Gestão por competências Gerenciais: noções e processos de desenvolvimento. In: RUAS, R. L. et al. (Orgs.). Os novos horizontes da Gestão: aprendizagem organizacional e competências. Porto Alegre: Bookman, 2005.

OHEMENG, F. L. K. Constraints in the Implementation of Performance Management Systems in Developing Countries: The Ghanaian Case. International Journal of Cross Cultural Management, v. 9, n. 1, p. 109-132, 2009. http://dx.doi.org/10.1177/1470595808101158

PARRY, S. Just What is a Competency?. Training, p. 58-64, June 1998.

PENROSE, E. T. The theory of the growth of the firm. 3rd ed. Oxford: Basil Blackwell, 1995. http:// dx.doi.org/10.1093/0198289774.001.0001

PRAHALAD, C. K.; HAMEL, G. Y. The core competence of the corporation. Harvard Business Review, May/ June 1990.

PRAHALAD, C. K.; HAMEL, G. Y. Competindo pelo futuro: estratégias inovadoras para obter o controle do seu setor e criar os mercados de amanhã. 2. ed. Rio de Janeiro: Campus, 1995.

RETOUR, D.; KROHMER, C. La compétence collective, maillon clé de la gestion des compétences. In: DEFÉLIX, C.; KLASFERD, A.; OIRY, E. Nouveaux regards sur la gestion des compétences. Paris: Vuibert, 2006. 
RETOUR, D. Le DRH de demain face au dossier compétences. Revue Management \& Avenir, v. 4, p. 187-200, 2005. http://dx.doi.org/10.3917/mav.004.0187

RETOUR, D. Progressos e Limites da Gestão por Competência na França. In: DUTRA, J. S.; FLEURY, M. T. L.; RUAS, R. L. (Orgs.). Competências: conceitos, métodos e experiências. São Paulo: Atlas, 2008.

RICHARDSON, R. J. et al. Pesquisa social: métodos e técnicas. São Paulo: Atlas, 1999.

RUANO, A. M. Gestão por Competência: Uma Perspectiva para a Consolidação da Gestão Estratégica de Recursos Humanos. Rio de Janeiro: Qualitymark, 2003.

RUAS, R. L. Gestão por Competências: uma contribuição à estratégia das organizações. In: RUAS, R. L.; ANTONELLO, C. S.; BOFF, L. H. (Orgs.). Os novos horizontes da Gestão: aprendizagem organizacional e competências. Porto Alegre: Bookman, 2005.

TEECE, D. J.; PISANO, G.; SHUEN, A. Dynamic capabilities and strategic management. Berkeley: Center for Research in Management, University of California, 1997.

TORQUATO, G. Cultura - poder - comunicação e imagem: fundamentos da nova empresa. São Paulo: Pioneira, 1991.

VALA, J. et al. Psicologia social das organizações: estudos em empresas portuguesas. 2. ed. Olivas: Celta, 1995.
WEICK, K. Sensemaking in organizations. Thousand Oaks, 1995.

WERNERFELT, B. A resource based view of the firm. Strategic Management Journal, v. 5, n. 2, p. 171-180, 1984. http:// dx.doi.org/10.1002/smj.4250050207

ZAGO, C. C. Modelo de Arquitetura da Cultura Organizacional. 2000. Tese (Doutorado em Engenharia de Produção)-Universidade Federal de Santa Catarina, Santa Catarina, 2000.

ZAGO, C. C. Cultura Organizacional : Dimensões Estruturais e Aspectos Dinâmicos. Revista Informação \& Sociedade, v. 15, n. 2, p. 63-93, 2005.

ZAGO, C. C.; SOUZA, C. C. B.; BEZERRA, L. A. M. Competências profissionais do administrador: uma análise comparativa entre as necessidades do mercado e a formação dos Administradores da Paraíba. Gestão. Org: Revista Eletrônica de Gestão Organizaciona, v. 5, n. 2, p. 211-225, 2007.

ZARIFFIAN, P. O modelo da competência: trajetória histórica, desafios atuais e propostas. Tradução de Eric Roland René Heneault. São Paulo: Senac, 2003.

ZULA, K. J.; CHERMACK, T. J. Integrative Literature Review: Human Capital Planning: A Review of Literature and Implications for Human Resource Development. Human Resource Development Review, v. 6, n. 3, p. 245-262, 2007. http://dx.doi.org/10.1177/1534484307303762 